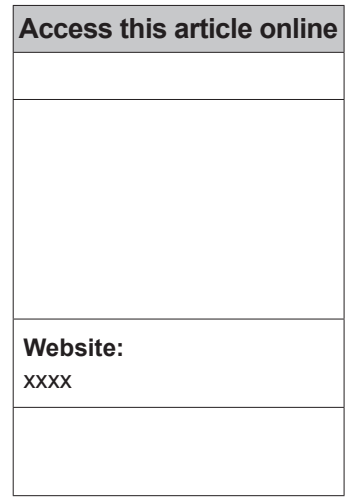

Department of

Experimental Medicine,

Sapienza University

of Rome, Systems

Biology Group Lab,

Viale Regina Elena,

${ }^{1}$ Department of Surgery

"Pietro Valdoni",

Sapienza University

of Rome, Via Antonio

Scarpa, ${ }^{2}$ Azienda

Policlinico Umberto I,

Viale del Policlinico,

${ }^{3}$ Department of

Clinical and Molecular

Medicine, Sapienza

University of Rome,

Viale Regina Elena,

Rome, Italy

Address for correspondence:

Prof. Mariano Bizzarri,

Via A. Scarpa 14, 00161

Rome, Italy.

E-mail: mariano.bizzarri@

uniroma1.it

Submission: 08-10-2014

Accepted: 17-10-2014

\title{
The tumor microenvironment as a target for anticancer treatment
}

\author{
M. Bizzarri, A. Cucina ${ }^{1,2}$, S. Proietti $i^{1,3}$
}

\begin{abstract}
:
Cancer is generally considered as a (pathological) microcosm emerging from a deregulated genome occurring in a single cell. Yet, this paradigm has encompassed several shortfalls, and it is now increasingly recognized that the overall framework is very much complex as previously thought. Indeed, the cell-stroma interaction plays a pivotal role in both cancer onset and prevention, by providing a set of biophysical and biochemical cues, which drive cell towards neoplastic transformation, eventually leading to metastasis. However, experimental and clinical evidences suggest that cancers can be induced to become quiescent, differentiate, die or form completely normal tissues, if provided with the correct set of complex signals, as conveyed by embryonic tissues or other microenvironmental cues. These data suggest that by manipulating cancer microenvironment may help in opening new avenues for therapeutic solutions.
\end{abstract}

Key words:

Cell-stroma interactions, tissue organization theory of carcinogenesis, tumor microenvironment

\section{Introduction}

T $\mathrm{t}$ is generally accepted that cancer is an Lirreversible disease that results from accumulated gene mutations and chromosomal abnormalities. This model has been proposed by the somatic mutation theory of cancer (SMT), which envisions understanding cancer at the cellular level of organization, while claiming that cancer is a problem of regulatory control of cell proliferation and invasiveness, mainly due to mutations and/or deregulation of special classes of genes, that is, oncogenes and suppressor genes. ${ }^{[1]}$ If cancers are caused by irreversible genetic changes, even accumulated during the process which leads from the initiation to the metastatic spreading of cancer, treatment will require that these cells must be killed or surgically removed to achieve a successful cure.

However, current treatments, grounded on the aforementioned SMT paradigm are disappointing and demonstrate that no further improvement can be obtained by conventional chemotherapy, and only slight advantage in overall survival rate has been reached since the introduction of the so-called target (gene)-based drugs. ${ }^{[2]}$ Indeed, despite some progress, conventional as well as "innovative" chemotherapeutic protocols failed in obtaining significant improvement in overall survival, given that the death rates from the prevailing form of tumors (breast, colon, and prostate cancers) show, at the best, a stable trend.$^{[3]}$ In a broader sense, there is a perception that cancer research is not progressing as fast as might be hoped from the investment in research. ${ }^{[4]}$ This evidence prompted someone to suggest that we are losing the "war on cancer". ${ }^{[5]}$

Even SMT supporters have recently acknowledged that the gene-based paradigm is facing increasing shortfalls and contradictions. Accordingly to Weinberg, the expected evidence did not turn out to vindicate explanations provided by SMT. Quoting him, "half a century of cancer research had generated an enormous body of observations [....] but there were essentially no insights into how the disease begins and progresses". ${ }^{[6]}$ Despite the expectations raised by "the Ames" axiom ("substances act as carcinogens because they have mutagenic activity"), it shortly turned out that most powerful carcinogens are actually not mutagen"; "but fortunately-as Weinberg candidly admits - I and others were not derailed by discrepant facts". Indeed, a whole series of "discrepant facts" were ignored, while acknowledging that their realistic evaluation would have flawed the dominant paradigm. ${ }^{[7]}$ Yet, despite this realization, the search for mutated oncogenes and/or tumor suppressor genes continued unabated up to the present. "However even this was an illusion, as only became apparent years later the identities of mutant cancer-causing genes varied dramatically from one type of tumor to the next. Each tumor seemed to represent a unique experiment of nature ${ }^{\prime \prime}{ }^{[6]}$ Moreover, the ever-changing genomic portrait, the high genomic instability and heterogeneity of cancer, represent an insurmountable hurdle, ${ }^{[8]}$ and makes almost impossible to achieve a successful personalized, gene-based treatment. ${ }^{[9]}$ Indeed, experimental data provided so far urge us to revisit the role of gene mutations in cancer, 
"suggesting that mechanisms for cancer initiation are broader than is typically thought." ${ }^{10]}$

\section{The tumor microenvironment}

A plausible, testable, alternative theory of carcinogenesis has been proposed already 15 years ago-the Tissue Organization Theory of Carcinogenesis (TOFT) - claiming that cancer arises from the deregulated interplay among cells and their microenvironment. ${ }^{[11]}$

Epithelial cells can becomedysfunctional if their microenvironment is severely perturbed. This control of epithelia by their stroma is a default condition in normal tissues, as adult organs do not change the composition, size or shape by uncontrolled remodeling. Therefore, rather than being a passive reaction to the cancer cell, the microenvironment might be a primary active factor in determining whether dysfunctional epithelial cells will be subject to neoplastic transformation, invading and further disrupting their local milieu, or, alternatively, merely become an indolent micro-hyperplasia or even be eliminated.

According to TOFT, the microenvironment represents the physical-biochemical support of the morphogenetic field, which drives epithelial cells toward differentiation and phenotype transformation, according to rules understandable only by means of a systems approach. ${ }^{[12]}$ Not only the microenvironment-cells interplay is a matter of "signaling interaction", but also, it involves biophysical factors and field-based effects, usually, overlooked by the current scientific mainstream. ${ }^{[13]}$ Lesser attention has been given to the explicitly highlighted premise of TOFT that states that the default state of all cells is proliferation. Notwithstanding, by challenging the implicit premise included in SMT that assumes that the default state of cells in metazoans is quiescence, it makes TOFT stand-alone from other theories of carcinogenesis. Briefly, TOFT considers that the cancer is a tissue-based disease and adopts proliferation as the default state of all cells. This latter aspect of TOFT has been discussed at length elsewhere. ${ }^{[14]}$

Studies on tumor microenvironment are dating back even from 1940, when microenvironment was shown to suppress skin carcinogenesis induced by chemical carcinogens. ${ }^{[15]}$ Since then, an increasing number of experimental data have demonstrated that the microenvironment actively contributes to carcinogenesis already since the first stages, by profoundly influencing many cellular processes such as growth, differentiation, and apoptosis. ${ }^{[16,17]}$ Discrete differences in extracellular matrix (ECM) composition and stiffness, selectively foster or inhibits proliferation, by modulating regulatory molecules of the cell cycle and the early response genes. ${ }^{[18-20]}$ The microenvironment regulates the transcription of genes associated with differentiating pathways ${ }^{[21,22]}$ and participates in shaping cells phenotypes, by modulating cell-stroma interactions and cytoskeleton architecture. ${ }^{[23,24]}$ Moreover, cell shape and microenvironmental cues may trigger programmed cell death signals, hence driving cells towards apoptosis. ${ }^{[25,26]}$ Changes in the microenvironment three-dimensional network or composition may lead to tissue fibrosis, augmented collagen cross-linking, and tissue stiffening, which have been associated to an increased risk of developing cancer. ${ }^{[27,28]}$ It is not trivial to recall that aging is associated to increase in both tissue stiffness and cancer incidence. ${ }^{[29]}$ In turn, tissue fibrosis and modification of physical-chemical properties of ECM may likely influence tumor onset and progression by regulating soluble factors involved in inflammation ${ }^{[30]}$ and angiogenesis. ${ }^{[31]}$

Participation of microenvironment in carcinogenesis is further highlighted by the observed changes in the phenotype of stromal cells residing within the tumor microenvironment. Both cancer-associated fibroblasts ${ }^{[32]}$ and endothelial cells, ${ }^{[33]}$ have been demonstrated to carry structural changes ${ }^{[34]}$ and molecular abnormalities that may actually foster cancer onset and development. ${ }^{[35-37]}$ Exposition of stroma to the chemical carcinogen induces stroma-dependent changes in epithelial cells towards cancerous transformation, by disrupting the normal stromal-epithelial interactions, whereas by treating directly the epithelial cells does not lead to any neoplastic transformation. ${ }^{[38]}$ Conversely, the malignant phenotype of tumor cells may be efficiently counteracted, eventually leading to a fully neoplastic reversion, by placing cancer cells into a normal three-dimensional-microenvironment, which provides appropriate biochemical and biophysical stimuli. ${ }^{\left[{ }^{[9,40]} \text { Similar }\right.}$ results have been confirmed by many other studies, ${ }^{[41,42]}$ thereby outlining that the main factor in driving the carcinogenic process lies on the cross-talk in between microenvironment and epithelial cells. ${ }^{[43]}$

\section{Tumor Microenvironment as a Target}

Such results are highly exciting and intriguing, as they suggest that, contrary to what has been thought until now, cancer can be actually viewed as a reversible process. ${ }^{[44]}$ Moreover, conversely, if cancer is a reversible process, then the entire carcinogenic paradigm must be changed accordingly. ${ }^{[45]}$ This is a highly provocative idea, but perhaps is the only opportunity to deal with cancer complexity and find an effective treatment.

Indeed, an increasing and compelling body of evidence provided by experimental studies and corroborated from clinical studies - suggests that cancers can be induced to become quiescent, differentiate, die or form completely normal tissues, if provided with the correct set of complex signals, as conveyed by embryonic tissues or other microenvironmental cues. $^{[46-48]}$

Moreover, many clinical reports show that different cancers can undergo a spontaneous regression, reverting toward a normal phenotype. Spontaneous disappearance or differentiation of animal and human cancers, such as stage-IV neuroblastoma, liver neoplasia, ${ }^{[49]}$ breast tumors, ${ }^{[50]}$ and many others, have been hitherto reported. ${ }^{[51]}$ Similarly, several studies have shown that by placing cancerous cells into a "normal" microenvironment - that is, by restoring a normal, strong morphogenetic field - the tumor phenotype may be reverted into a normal one, eventually promoting a de novo cell and tissue differentiating process. Cancer cells exposed to embryonic morphogenetic fields ${ }^{[52-55]}$ or cultured in three-dimensional-reconstructed biological microenvironment mimicking the normal tissue architecture, undergo entrenched processes of apoptosis and differentiation, eventually ending up into the reprogramming of a "normal" phenotype. ${ }^{[56,57]}$ Usually, this evidence is either "neutralized", arguing that microenvironment may activate other unknown genetic pathways through unspecified ways or else ignored, by 
considering it a "funny" exception. The truth is that within the theoretical boundaries provided by SMT such results cannot be explained, and actually its advocates do not even try to do so. Indeed, if cancer onset were truly an event due to the accumulation of mutations in a few key-genes, once the threshold has been crossed there would be no way back towards normality. On the contrary, such paradoxical data constitute a pivotal element of TOFT, which posits that the microenvironment represents the physical-biochemical support of the morphogenetic field which drives epithelial cells towards differentiation and phenotype transformation. ${ }^{[58,59]}$

Cancer-reversion induced by the microenvironment has been frequently ascribed to some key-molecular morphogens or gene modification affecting cell components of stroma. ${ }^{[60]}$ Consequently a wide subset of specific drug has been designed to target selective components, including chemo-attractants produced by tumor-associated fibroblasts, angiogenetic factors (Fibrinogen- $\beta$, vascular endothelial growth factor [VEGF] $){ }^{[61,62]}$ fibrotic processes, ${ }^{[63]}$ metalloproteinases (MMP), ${ }^{[64]}$ urokinase plasminogen activator, ${ }^{[65]}$ integrins, ${ }^{[66]}$ focal adhesion kinases, ${ }^{[67]}$ TGF- $\beta 1^{[68]}$ and many others. Until date, some promising results have been obtained, even if such new attempts have been flawed by an approach that still relies on a reductionist-based framework.

Indeed, studies performed by engineering the tumor microenvironment and/or by treating the stroma with factors capable of rewiring its physical-chemical properties show that cancer formation can be promoted or reversed by altering the mechanics or structure of the ECM, ${ }^{[24,69,70]}$ by modifying the connective structure of tissue stroma ${ }^{[38,71]}$ or even changing the bioelectrical milieu ${ }^{[72,73]}$ or the systems physical properties by acting on the gravitational field. ${ }^{[74]}$ Engineered bio-mimetic scaffolds mimicking the embryonic ability in reverting cancer into normal epithelium, could allow obtaining materials to be applied at the tumor resection sites in order to prevent local tumor recurrences.

Thinking about the cancer microenvironment as a "systems target", entails taking into consideration some key issue in order to achieve a biological and clinical result. Thus, we have to look closely to some meaningful example of cancer management and reversion induced by manipulating the tumor microenvironment in order to gain fruitful insights about the mechanism behind that process.

\section{Tumor Reversion and Management}

Microenvironment drives hematological malignancies

Some recent papers outline how, even without any mutations, changes in the hematological niche as well as microenvironmental defects in retinol-binding receptors, may efficiently induce hematological malignancies. These studies demonstrated that the microenvironment, and specifically non-hematological cells, plays a pivotal role in enabling bone marrow cells to undergo a proper differentiating pathway, eventually inhibiting the occurrence of myeloproliferative disorders (MPD). Indeed bone forming osteoblasts have been recognized as a critical component of the hematopoietic stem cell (HSC) niche. ${ }^{[75]}$ The bone marrow microenvironment contributes in regulating HSC differentiation and also in preventing cancerous transformation..$^{[76]}$ Indeed, an abnormal $\beta$-catenin distribution, leading to increased activated $\beta$-catenin levels in the nucleus of the osteoblasts, has been demonstrated to trigger changes in HSCs, enhancing a shift toward the cancerous phenotype, that is, inducing acute myeloid leukemia (AML). As $\beta$-catenin interacts with E-cadherin in transducing mechanic stimuli from the microenvironment to the cytoskeleton, one could hypothesize that abnormalities in $\beta$-catenin distribution will likely affect the overall cell architecture and the correlated functions. A tight link in between shape and biological function has been indeed observed by many studies. Those experimental results have been confirmed by investigations carried out on AML patients, showing nuclear (activated) $\beta$-catenin in osteoblasts and upregulation of Notch signaling in hematopoietic cells, whereas nuclear staining of $\beta$-catenin was absent in healthy controls. ${ }^{[77]}$ These findings showed that the modification in osteoblasts may influence the HSC niche and are sufficient enough to drive the development of leukemia in mice. Deregulated expression as well as abnormal localization of $\beta$-catenin within the nucleus has been observed in different cancers and currently that feature is thought as key factor in carcinogenesis given that $\beta$-catenin modulation could influence many systemic properties of both cancer cells and their microenvironment. Thus, down-regulating $\beta$-catenin and its downstream correlated pathways, may represent a new, promising target in cancer drug discovery. However, to our best knowledge, no attempts have been so far performed to identify a pharmacological "bullet" able not only in reducing $\beta$-catenin levels, but also in inhibiting its nuclear localization and further activation. Fortunately, a few selected natural compounds, belonging to the class of pholyphenols (epigallo-catechins, gallic acid, quercetin, procyanidins and many others), usually extracted from green tea and grape seed, display such outstanding property: $\beta$-catenin in cancer cells treated with grape seed or green tea extracts undergo a cytoplasmic and cortical redistribution, while control cells exhibited the protein mainly in the nucleus. Moreover, after 48-h treatment the overall $\beta$-catenin expression was dramatically reduced; consequently, many other $\beta$-catenin-linked pathways were down-regulated. ${ }^{[78]}$

\section{Retinol and hematological malignancies}

Retinol acid receptors (RAR) display a wide range of effects on both cancer cells. This effect is triggered by the Vitamin A derivative, all-trans retinoic acid (ATRA) the naturally occurring ligand for all subtypes of RARs. More intriguingly, however, lack of RARs within the hematological niche, induces and sustains the development of MPD. Indeed, the hematological malignancies triggered in RAR-null mice are not intrinsic to the hematopoietic compartment, but it is induced by the RAR-null microenvironment. In RAR-null mice, the architecture of the hematological niche, that is, the three-dimensional structure of the microenvironment, is profoundly disrupted: Histological sections ofunder calcified tibiae revealed significantly reduced trabecular bone and increased osteoclasts number. Release of some inflammatory cytokines - like tumor necrosis factor (TNF) - was concomitantly increased. As the myelodisplastic syndrome in such cases is partially inhibited by blocking TNF release, it can be argued that RARs deficiency promotes MPD also by fostering an inflammatory-like milieu. By analogy, even Vitamin A deficiency can result in myeloproliferation. ${ }^{[79]}$ Retinoic acid 
receptors regulate many different gene products, and aberrant expression or function of RARs has been identified in many different diseased states. It is likely that there are multiple contributing factors to the microenvironment-induced MPS observed in RARs null-animals, but it must be stressed that in such model micro environmental deregulation can be deemed the "the sole causative mechanism for MPS". In turn, it is of outmost interest that pleiotropic activities exerted by retinol derivatives have been demonstrated to efficiently counteract MPD and even some forms of leukemia, as the promyelocytic leukemia. ${ }^{[80]}$

\section{Embryonic microenvironment}

Compelling evidence has demonstrated that embryonic fields as well as soluble morphogens extracted from embryonic, pluripotent cells or from stem cells may efficiently inhibit cancer growth, promote apoptosis or induce phenotypic tumor reversion, documented by morphological, biochemical, behavioral as well as metabolomic features. ${ }^{[71]}$ These effects have been observed in vitro ${ }^{[55,81-84]}$ and also confirmed in a few selected studies, mainly carried out on advanced cancers ${ }^{[85]}$ or on hepatocellular carcinoma (HPC) patients. ${ }^{[86,87]}$ Namely, a randomized study has ascertained a significant advantage in advanced HPC patients (refractory to previous multi-drugs chemotherapy), treated with proteins extracted from Zebrafish embryos. An objective response rate of about $67 \%$ was recorded in the treated arm when compared to the control group, leading to a long-lasting disease-free interval up to 20 months. ${ }^{[88]}$ However, it is quite puzzling to understand why those patients achieved a so remarkable response. Indeed, no single active component has been so far identified within the crude protein extract from Zebrafish embryo, or from other conditioned embryo milieu that could explain the observed pharmacological effect, even if antiproliferative as well as pro-apoptotic activities have been ascribed to the protein extract considered as a whole. ${ }^{\left[{ }^{[9]}\right.}$ Embryo and stem cell-dependent microenvironment may likely act by modifying some biophysical cues, as well as through soluble morphogens, involving several key pathways: ${ }^{[90-92]}$ Both of these mechanism act by reshaping the morphogenetic field in which cancer cells are embedded. ${ }^{[93]}$

\section{Collagen as a target}

The overall architecture of the microenvironment, and specifically the three-dimensional structure of the ECM, is largely dependent to collagen concentration, posttranslational modification (leading to structural remodeling through cross-linking) and proteolysis. At all of these levels, collagen has been shown to be deregulated in cancerous tissues, resulting in an abnormal ECM architecture. These changes are likely to affect ECM stiffness, as well as many other biophysical properties (viscosity, $\mathrm{pH}$, hydration), which in turn may profoundly affect molecules (hormones, nutrients) transport, cell adhesion to the substrate and cell cytoskeleton configuration as well. Collagen and ECM cannot be longer considered as an inert scaffolding protein and migration barrier, given their interaction with epithelial cells may efficiently modulate gene expression, enzymatic activity and eventually cancer transformation. ${ }^{[94]}$

Analysis of human tumors has revealed indeed an association between collagen expression or collagen modifying enzymes and poor prognosis, ${ }^{[95,96]}$ supporting the notion that collagen remodeling is highly relevant to human cancer progression. In turn, a wide range of collagen-targeting molecules and drugs have been hitherto demonstrated to significantly influence cancer onset and development. Ascorbic acid, inhibitors of hyaluronidase ${ }^{[97]}$ and of Lysyl-oxidase, ${ }^{[98]}$ as well as many polyphenols extracted from green tea or grapes, ${ }^{[99]}$ have been shown to modulate ECM, matrix composition and stiffness. Additionally, several experimental and clinical studies demonstrated that those compounds exert a significant clinical activity, both as chemopreventive agents as well as anti-cancer drugs. ${ }^{[100,101]}$ Namely, it is worth of noting that ascorbic acid, whose anticancer effects are usually ascribed to its anti-oxidant properties, exerts even a more relevant effect by ensuring proper collagen metabolism, matrix remodeling, MMPs inhibition, preserving by this way the "stroma homeostasis" through different, entrenched mechanisms. ${ }^{[102-104]}$ Moreover, even if some disappointing results have been reported, there is little doubt that Vitamin C displays an important chemopreventive activity ${ }^{[105]}$ and can lead to a significant clinical benefit in integrative oncologic settings. ${ }^{[106,107]}$

Collagen structure may significantly influence several parameters and functions by modulating both matrix and cells stiffness. Indeed, a more entrenched network performed by the interaction among types I and IV collagen foster integrin-mediated cell adhesion to substrate and enhances tissue stiffness. ${ }^{[108,109]}$ Enhanced stiffness promotes cytoskeleton remodeling, and interstitial fluid pressure (IFP) increase, thus hampering drug and molecular flux. ${ }^{[110]}$ On the contrary, by decreasing collagen fibril size or matrix density through collagenases addiction, interstitial pressure drops and drugs delivery is raised. ${ }^{[111,112]}$ Consequently, improved drug responses have been achieved when the collagen content in tumors has been reduced. ${ }^{[113]}$

Indeed, strategies to overcome the environmental barriers constituted by abnormal microenvironmental vascular structure or increased stiffness and viscosity, have yielded some promising results. ${ }^{[114]}$ The two phenomena are closely linked: Vessel normalization, ameliorate tissue stiffness and reduces the interstitial pressure and this result not only enhances the drugs uptake, but will likely normalize the micro environmental metabolomic fingerprint. The administration of VEGF-receptor2-blocking antibodies, platelet derived growth factor antagonists, and TGF $\beta$ inhibitors, among others, effectively reduces IFP, resulting in enhanced drug uptake. ${ }^{[115-117]}$

A renewed interest in collagen study in cancer is taking off, as abnormal expression, proteolysis and structure of the "collagen network" influence cellular functions to elicit multiple effects on tumors, including proliferation, initiation, invasion, metastasis, and therapy response. ${ }^{[118]}$

However, how collagen changes precisely influences tumor onset and development is still challenging. Namely, there is an urgent need to correlate collagen modification to cytoskeleton dynamics and cell function, in order to develop tractable methods to manipulate biochemical composition, architectural features and mechanical properties of collagen. Given that some apparently contradictory results have been reported, 
demonstrating that both increased ${ }^{[119]}$ and decreased ${ }^{[120]}$ deposition of collagen can be associated with cancer growth, it is mandatory to outline that the main effect of collagen are mediated by its network architecture and/or by the dynamics of its remodeling rather than solely by protein level. Consequently, engineers and cancer biologists are beginning to find together the way to reproduce synthetic work Scaffolds that can induce cultured tumor cells to better mimic the in vivo phenotype. ${ }^{[121]}$ These studies highlight how important is regenerating a 'stem cell niche' with correct physical and chemical properties, given that providing cytokines alone is far from be sufficient. ${ }^{[122]}$

Chronic inflammatory processes and the microenvironment The highly ordered sequence of events that undergo during inflammation and repair may become chaotically disorganized during chronic unresolved inflammation. This process may promote microenvironment disorganization, eventually leading to cancer onset. The "chaotic" local microenvironment rearrangement induced by the chronic inflammatory reaction prompted HF Dvorak to suggest that tumors are "wounds that do not heal." [123] This process can be viewed as an abortive attempt to re-establish homeostasis through (abnormal) tissue remodeling, where the survival and transformation of epithelial cells is paradoxically fostered by both cells and microenvironmental components participating in the inflammatory reaction. ${ }^{[124]}$ Indeed, the onset of several tumors has been associated to chronic, abnormal inflammatory processes. ${ }^{[30]}$

A special interest has been aroused by Nitric oxide, IкB kinase, ${ }^{[125]}$ the upstream kinase that activates NF- $\mathrm{kB}, \mathrm{TNF}-\alpha^{[126]}$ COX-2 proteins, ${ }^{[127,128]}$ interleukins (IL-1), IL6, and IL-8, ${ }^{[129]}$ and, consequently, many of these components have been recognized as potential targets for anticancer treatment given that it has long been recognized that by reducing chronic inflammation would lower the risk of developing cancer. Indeed, epidemiological studies have demonstrated that people taking anti-inflammatory drugs have a clear reduction in their risk of developing cancer. ${ }^{[130,131]}$ In addition, preliminary clinical trials demonstrated a significant benefit in treating cancer patients with synthetic as well as natural anti-inflammatory drugs. ${ }^{[132,133]}$ Overall, these pharmacological agents do not recognize a single, specific target, given that the multi-facetted activities of the administered drugs (anti-proliferative, angiostatic, antinflammatory, metabolic activity, immunomodulatory), and their differential cell-specific activities, the exact mechanisms of action of the selected drug combinations are difficult to pin down. Instead, these substances are likely to influence the cell-microenvironment as a whole, displaying both genomic and non-genomic effects. ${ }^{[134,135]}$

Paradoxical effects of compounds targeting the microenvironment

Many substances able to target the cancer microenvironment share the uncommon property to act in a paradoxical manner, that is, by exerting opposite effects on different cells or even in different tissues. For instance, bioflavonoids, melatonin and even Vitamin C are well-known to be potent scavenging free radicals agents in normal tissues. Instead, they promote reactive species release in cancerous cells, thus acting as pro-apoptotic factors. ${ }^{[136-138]}$
A special case in point is represented by polyphenols extracted from grape and tea, which exert many invaluable anticancer effects. Yet, interest in their clinical use comes from the observation by which such compounds behave as an "intelligent bullet", given that they can influence systems properties by distinguishing in between normal and cancer cells, triggering even opposite effects. ${ }^{[139]}$ As evidenced for other natural molecules (melatonin, ${ }^{[140]}$ retinol ${ }^{[141]}$ ), cell proteins (TGF- $\beta$ ) or collagen modifiers (hyaluronidase inhibitors, ${ }^{[142]}$ Lysyl-oxidase ${ }^{[143]}$ and Vitamin $C^{[144,145]}$ ), this meaningful feature could likely be ascribed to the different biophysical context which enables the system to differentially respond to a same cue.

Perhaps the best studied example of molecular paradoxes in cancer is represented by TGF- $\beta$ behavior. ${ }^{[146]}$ Both anticancer as well as cancer-promoting effects have been alternatively ascribed to TGF- $\beta$, until it becomes clear that the "dichotomous" nature of this molecule can be understood only by looking at the tissue-context in which TGF- $\beta$ is called upon to exert a biological function. ${ }^{[147]}$ Indeed, tumor stroma not only plays an important role during cancer initiation and progression, but also in determining whether TGF- $\beta$ suppresses or promotes tumor formation. ${ }^{[148]}$ That challenging puzzle can be solved by referring data to a higher (tissue) level of observation and by adopting a systems approach. For instance, TGF- $\beta$ may trigger opposite outputs depending on the tissue stiffness; under mechanically unloaded conditions (floating matrices), TGF- $\beta$ stimulated contraction directly as an agonist and indirectly by preactivating cells to express the myofibroblast phenotype, whereas, under mechanically loaded conditions (stressed matrices), TGF- $\beta$ had no direct agonist effect on contraction. ${ }^{[149]}$ That example highlights how when the cell-microenvironment interactions are kept in consideration, apparently conflicting results end up as such, and paradoxes may likely find a compelling explanation.

\section{Conclusion}

For a while, cancer has been considered like a Spinoza's monad, that is, as a microcosm emerging from a deregulated genome occurring in a single cell. Yet, that paradigm has encompassed several shortfalls and it is now increasingly recognized that the overall framework is very much complex that previously thought. We have to "revise the very definition of the term "carcinoma" (currently defined in classical terms as a malignancy derived from epithelial cells), and [...] we need to regard carcinogenesis and carcinomas as phenomena that occur in tissues, not in individual cancer cells. From this perspective, the microenvironment becomes an integral, essential part of the cancer". ${ }^{[150]}$

These evidences suggest that physical cues conveyed by stroma or biochemical compounds acting through a pleiotropic-system manner may be eventually more efficient than selective targeted-based drugs and could thereby open new avenues for therapeutic solutions. Conversely, it is now essential to develop new integrated therapeutic strategies focused of targeting the tumor microenvironment, in order to prevent and eventually cure cancer. ${ }^{[151]}$

The successful results obtained in treating even few selected cancers through microenvironment-drug modifiers, have 
firmly established the paradigm of "differentiation therapy" as a valid approach for the reversion of malignancy in the treatment of neoplasia in human patients. It remains the task to identify newly and more efficient compounds able to globally active in resetting the cell-stroma interactions. That issue can be pursued by combining well-designed pharmacological substances, as well as nutrients and other natural compounds able to selectively target the microenvironment. ${ }^{[152,153]}$

A compelling body of evidence suggests that the potential for cancer reversibility exists. However, rigorous experimental characterization of how this process proceeds is necessary before the existing research establishment should take notice and radically change its direction.

\section{References}

1. Hanahan D, Weinberg RA. The hallmarks of cancer. Cell 2000;100:57-70.

2. American Cancer Society-Cancer Facts and Figures, 2010. Available from: http://www.cancer.org/research/cancerfactsstatistics / cancerfactsfigures2010/index. [Last accessed in 2014].

3. Autier P, Boniol M, Gavin A, Vatten LJ. Breast cancer mortality in neighbouring European countries with different levels of screening but similar access to treatment: Trend analysis of WHO mortality database. BMJ 2011;343:d4411.

4. Hawkes N. High cost of cancer treatment doesn't reflect benefits, say specialists. BMJ 2011;343:d6220.

5. El-Deiry WS. Are we losing the war on cancer? Cancer Biol Ther 2013;14:1189-90.

6. Weinberg RA. Coming full circle-from endless complexity to simplicity and back again. Cell 2014;157:267-71.

7. Baker SG, Kramer BS. Paradoxes in carcinogenesis: New opportunities for research directions. BMC Cancer 2007;7:151.

8. Tong D, Jiang J. Complex behaviours - new targets against cancer. Nat Rev Clin Oncol 2013;10.

9. Meric-Bernstam F, Mills GB. Overcoming implementation challenges of personalized cancer therapy. Nat Rev Clin Oncol 2012;9:542-8.

10. Versteeg R. Cancer: Tumours outside the mutation box. Nature 2014;506:438-9.

11. Soto AM, Sonnenschein C. The tissue organization field theory of cancer: A testable replacement for the somatic mutation theory. Bioessays 2011;33:332-40.

12. Soto AM, Sonnenschein C. Is systems biology a promising approach to resolve controversies in cancer research? Cancer Cell Int 2012;12:12.

13. Bizzarri M, Pasqualato A, Cucina A, Pasta V. Physical forces and non linear dynamics mould fractal cell shape: Quantitative morphological parameters and cell phenotype. Histol Histopathol 2013;28:155-74.

14. Sonnenschein C, Soto AM. The Society of Cells: Cancer and Control of Cell Proliferation. New York, NY, USA: Springer; 1999.

15. Berenblum I, Shubik P. An experimental study of the initiating state of carcinogenesis, and a re-examination of the somatic cell mutation theory of cancer. Br J Cancer 1949;3:109-18.

16. Bissell MJ, Barcellos-Hoff MH. The influence of extracellular matrix on gene expression: Is structure the message? J Cell Sci Suppl 1987;8:327-43.

17. van den Hooff A. Stromal involvement in malignant growth. Adv Cancer Res 1988;50:159-96.

18. Rana B, Mischoulon D, Xie Y, Bucher NL, Farmer SR. Cell-extracellular matrix interactions can regulate the switch between growth and differentiation in rat hepatocytes: Reciprocal expression of $\mathrm{C} / \mathrm{EBP}$ alpha and immediate-early growth response transcription factors. Mol Cell Biol 1994;14:5858-69.
19. Huang S, Chen CS, Ingber DE. Control of cyclin D1, p27(Kip1), and cell cycle progression in human capillary endothelial cells by cell shape and cytoskeletal tension. Mol Biol Cell 1998;9:3179-93.

20. Dike LE, Ingber DE. Integrin-dependent induction of early growth response genes in capillary endothelial cells. J Cell Sci 1996;109:2855-63.

21. Roskelley CD, Desprez PY, Bissell MJ. Extracellular matrix-dependent tissue-specific gene expression in mammary epithelial cells requires both physical and biochemical signal transduction. Proc Natl Acad Sci U S A 1994;91:12378-82.

22. Boudreau N, Myers C, Bissell MJ. From laminin to lamin: Regulation of tissue-specific gene expression by the ECM. Trends Cell Biol 1995;5:1-4.

23. Chen CS, Mrksich M, Huang S, Whitesides GM, Ingber DE. Geometric control of cell life and death. Science 1997;276:1425-8.

24. Paszek MJ, Zahir N, Johnson KR, Lakins JN, Rozenberg GI, Gefen A, et al. Tensional homeostasis and the malignant phenotype. Cancer Cell 2005;8:241-54.

25. Meredith JE Jr, Fazeli B, Schwartz MA. The extracellular matrix as a cell survival factor. Mol Biol Cell 1993;4:953-61.

26. Boudreau N, Sympson CJ, Werb Z, Bissell MJ. Suppression of ICE and apoptosis in mammary epithelial cells by extracellular matrix. Science 1995;267:891-3.

27. Colpaert CG, Vermeulen PB, Fox SB, Harris AL, Dirix LY, Van Marck EA. The presence of a fibrotic focus in invasive breast carcinoma correlates with the expression of carbonic anhydrase IX and is a marker of hypoxia and poor prognosis. Breast Cancer Res Treat 2003;81:137-47.

28. Martin LJ, Boyd NF. Mammographic density. Potential mechanisms of breast cancer risk associated with mammographic density: Hypotheses based on epidemiological evidence. Breast Cancer Res 2008;10:201.

29. Szauter KM, Cao T, Boyd CD, Csiszar K. Lysyl oxidase in development, aging and pathologies of the skin. Pathol Biol (Paris) 2005;53:448-56.

30. Balkwill F, Charles KA, Mantovani A. Smoldering and polarized inflammation in the initiation and promotion of malignant disease. Cancer Cell 2005;7:211-7.

31. Coussens LM, Raymond WW, Bergers G, Laig-Webster M, Behrendtsen $\mathrm{O}$, Werb Z, et al. Inflammatory mast cells up-regulate angiogenesis during squamous epithelial carcinogenesis. Genes Dev 1999;13:1382-97.

32. Hu M, Yao J, Cai L, Bachman KE, van den Brûle F, Velculescu V, et al. Distinct epigenetic changes in the stromal cells of breast cancers. Nat Genet 2005;37:899-905.

33. St Croix B, Rago C, Velculescu V, Traverso G, Romans KE, Montgomery E, et al. Genes expressed in human tumor endothelium. Science 2000;289:1197-202.

34. Giannelli G, Milillo L, Marinosci F, Lo Muzio L, Serpico R, Antonaci S. Altered expression of integrins and basement membrane proteins in malignant and pre-malignant lesions of oral mucosa. J Biol Regul Homeost Agents 2001;15:375-80.

35. Chung LW, Baseman A, Assikis V, Zhau HE. Molecular insights into prostate cancer progression: The missing link of tumor microenvironment. J Urol 2005;173:10-20.

36. Chung LW, Chang SM, Bell C, Zhau H, Ro JY, von Eschenbach AC. Prostatic carcinogenesis evoked by cellular interaction. Environ Health Perspect 1988;77:23-8.

37. Bindra RS, Glazer PM. Genetic instability and the tumor microenvironment: Towards the concept of microenvironment-induced mutagenesis. Mutat Res 2005;569:75-85.

38. Maffini MV, Soto AM, Calabro JM, Ucci AA, Sonnenschein C. The stroma as a crucial target in rat mammary gland carcinogenesis. J Cell Sci 2004;117:1495-502.

39. Vosseler S, Mirancea N, Bohlen P, Mueller MM, Fusenig NE. Angiogenesis inhibition by vascular endothelial growth factor receptor-2 blockade reduces stromal matrix metalloproteinase 
expression, normalizes stromal tissue, and reverts epithelial tumor phenotype in surface heterotransplants. Cancer Res 2005;65:1294-305.

40. Hendrix MJ, Seftor EA, Seftor RE, Kasemeier-Kulesa J, Kulesa PM, Postovit LM. Reprogramming metastatic tumour cells with embryonic microenvironments. Nat Rev Cancer 2007;7:246-55.

41. Barcellos-Hoff MH, Ravani SA. Irradiated mammary gland stroma promotes the expression of tumorigenic potential by unirradiated epithelial cells. Cancer Res 2000;60:1254-60.

42. Nguyen DH, Oketch-Rabah HA, Illa-Bochaca I, Geyer FC, Reis-FilhoJS, MaoJH, et al. Radiation acts on the microenvironment to affect breast carcinogenesis by distinct mechanisms that decrease cancer latency and affect tumor type. Cancer Cell 2011;19:640-51.

43. Kenny PA, Bissell MJ. Tumor reversion: Correction of malignant behavior by microenvironmental cues. Int J Cancer 2003;107:688-95.

44. Bizzarri M, Giuliani A. Representing cancer cell trajectories in a phase-space diagram: Switching cellular states by biological phase transitions. In: Dehmer M, Emmert-Streib F, Graber A, Salvador A, editors. Applied Statistics for Network Biology: Methods in Systems Biology. KGaA, Weinheim, Germany: WileyVCH Verlag GmbH and Co; 2011.

45. Ingber DE. Can cancer be reversed by engineering the tumor microenvironment? Semin Cancer Biol 2008;18:356-64.

46. Mammoto A, Ingber DE. Cytoskeletal control of growth and cell fate switching. Curr Opin Cell Biol 2009;21:864-70.

47. Ellison ML, Ambrose EJ, Easty GC. Differentiation in a transplantable rat tumour maintained in organ culture. Exp Cell Res 1969;55:198-204.

48. Park CC, Bissell MJ, Barcellos-Hoff MH. The influence of the microenvironment on the malignant phenotype. Mol Med Today 2000;6:324-9.

49. Tatematsu M, Nagamine $Y$, Farber E. Redifferentiation as a basis for remodeling of carcinogen-induced hepatocyte nodules to normal appearing liver. Cancer Res 1983;43:5049-58.

50. Horii R, Akiyama F, Kasumi F, Koike M, Sakamoto G. Spontaneous " healing" of breast cancer. Breast Cancer 2005;12:140-4.

51. Challis GB, Stam HJ. The spontaneous regression of cancer. A review of cases from 1900 to 1987. Acta Oncol 1990;29:545-50.

52. Bizzarri M, Cucina A, Biava PM, Proietti S, D'Anselmi F, Dinicola $\mathrm{S}$, et al. Embryonic morphogenetic field induces phenotypic reversion in cancer cells. Review article. Curr Pharm Biotechnol 2011;12:243-53.

53. Lakshmi MS, Sherbet GV. In: Sherbet GV, Karger S, editors. Embryonic and Tumour Cell Interactions. New York: S. Karger; 1974. p. 380-99.

54. Pierce GB, Wallace C. Differentiation of malignant to benign cells. Cancer Res 1971;31:127-34.

55. Chung LW, Zhau HE, Ro JY. Morphologic and biochemical alterations in rat prostatic tumors induced by fetal urogenital sinus mesenchyme. Prostate 1990;17:165-74.

56. D'Anselmi F, Masiello MG, Cucina A, Proietti S, Dinicola S, Pasqualato A, et al. Microenvironment promotes tumor cell reprogramming in human breast cancer cell lines. PLoS One 2013;8:e83770.

57. Bissell MJ, Kenny PA, Radisky DC. Microenvironmental regulators of tissue structure and function also regulate tumor induction and progression: The role of extracellular matrix and its degrading enzymes. Cold Spring Harb Symp Quant Biol 2005;70:343-56.

58. Krause S, Maffini MV, Soto AM, Sonnenschein C. The microenvironment determines the breast cancer cells' phenotype: Organization of MCF7 cells in 3D cultures. BMC Cancer 2010;10:263.

59. Bizzarri M, Cucina A. Tumor and the microenvironment: A chance to reframe the paradigm of carcinogenesis? Biomed Res Int 2014;2014:934038.

60. Fukumura D, Jain RK. Tumor microenvironment abnormalities:
Causes, consequences, and strategies to normalize. J Cell Biochem 2007;101:937-49.

61. Papetti M,Herman IM. Mechanisms of normal and tumor-derived angiogenesis. Am J Physiol Cell Physiol 2002;282:C947-70.

62. Benjamin LE, Golijanin D, Itin A, Pode D, Keshet E. Selective ablation of immature blood vessels in established human tumors follows vascular endothelial growth factor withdrawal. J Clin Invest 1999;103:159-65.

63. Iyer SN, Gurujeyalakshmi G, Giri SN. Effects of pirfenidone on transforming growth factor-beta gene expression at the transcriptional level in bleomycin hamster model of lung fibrosis. J Pharmacol Exp Ther 1999;291:367-73.

64. Rowinsky EK, Humphrey R, Hammond LA, Aylesworth C, Smetzer L, Hidalgo M, et al. Phase I and pharmacologic study of the specific matrix metalloproteinase inhibitor BAY 12-9566 on a protracted oral daily dosing schedule in patients with solid malignancies. J Clin Oncol 2000;18:178-86.

65. Andreasen PA, Kjøller L, Christensen L, Duffy MJ. The urokinase-type plasminogen activator system in cancer metastasis: A review. Int J Cancer 1997;72:1-22.

66. Sethi T, Rintoul RC, Moore SM, MacKinnon AC, Salter D, Choo C, et al. Extracellular matrix proteins protect small cell lung cancer cells against apoptosis: A mechanism for small cell lung cancer growth and drug resistance in vivo. Nat Med 1999;7:186-91.

67. Morin PJ. Drug resistance and the microenvironment: Nature and nurture. Drug Resist Updat 2003;6:169-72.

68. Carmeliet P. Angiogenesis in health and disease. Nat Med 2003;9:653-60.

69. Ingber DE, Madri JA, Jamieson JD. Role of basal lamina in neoplastic disorganization of tissue architecture. Proc Natl Acad Sci U S A 1981;78:3901-5.

70. Huang $S$, Ingber DE. Cell tension, matrix mechanics, and cancer development. Cancer Cell 2005;8:175-6.

71. D'Anselmi F, Valerio M, Cucina A, Galli L, Proietti S, Dinicola S, et al. Metabolism and cell shape in cancer: A fractal analysis. Int J Biochem Cell Biol 2011;43:1052-8.

72. Levin M. Bioelectromagnetics in morphogenesis. Bioelectromagnetics 2003;24:295-315.

73. Levin M, Thorlin T, Robinson KR, Nogi T, Mercola M. Asymmetries in $\mathrm{H} / \mathrm{K}$-ATPase and cell membrane potentials comprise a very early step in left-right patterning. Cell 2002;111:77-89.

74. Pisanu ME, Noto A, De Vitis C, Masiello MG, Coluccia P, Proietti S, et al. Lung cancer stem cell lose their stemness default state after exposure to microgravity. Biomed Int 2014;2014:470253.

75. Calvi LM, Adams GB, Weibrecht KW, Weber JM, Olson DP, Knight MC, et al. Osteoblastic cells regulate the haematopoietic stem cell niche. Nature 2003;425:841-6.

76. Zhang J, Niu C, Ye L, Huang H, He X, Tong WG, et al. Identification of the haematopoietic stem cell niche and control of the niche size. Nature 2003;425:836-41.

77. Kode A, Manavalan JS, Mosialou I, Bhagat G, Rathinam CV, Luo $\mathrm{N}$, et al. Leukaemogenesis induced by an activating $\beta$-catenin mutation in osteoblasts. Nature 2014;506:240-4.

78. Dinicola S, Pasqualato A, Cucina A, Coluccia P, Ferranti F, Canipari R, et al. Grape seed extract suppresses MDA-MB231 breast cancer cell migration and invasion. Eur J Nutr 2014;53:421-31.

79. Kuwata T, Wang IM, Tamura T, Ponnamperuma RM, Levine R, Holmes KL, et al. Vitamin A deficiency in mice causes a systemic expansion of myeloid cells. Blood 2000;95:3349-56.

80. Warrell RP Jr, Frankel SR, Miller WH Jr, Scheinberg DA, Itri LM, Hittelman WN, et al. Differentiation therapy of acute promyelocytic leukemia with tretinoin (all-trans-retinoic acid). N Engl J Med 1991;324:1385-93.

81. Biava PM, Fiorito A, Negro C, Mariani M. Effects of treatment with embryonic and uterine tissue homogenates on Lewis lung carcinoma development. Cancer Lett 1988;41:265-70.

82. DeCosse JJ, Gossens CL, Kuzma JF, Unsworth BR. Breast 
cancer: Induction of differentiation by embryonic tissue. Science 1973;181:1057-8.

83. Ferranti F, D'Anselmi F, Caruso M, Lei V, Dinicola S, Pasqualato A, et al. TCam-2 seminoma cells exposed to egg-derived microenvironment modify their shape, adhesive pattern and migratory behaviour: A molecular and morphometric analysis. PLoS One 2013;8:e76192.

84. Qiao L, Xu Z, Zhao T, Zhao Z, Shi M, Zhao RC, et al. Suppression of tumorigenesis by human mesenchymal stem cells in a hepatoma model. Cell Res 2008;18:500-7.

85. Bizzarri M, Facco R, Ielapi T, Frati L. The embryonic and maternal regulatory factor as a palliative therapy for advanced solid tumours. J Tumor Marker Oncol 2002;17:31-6.

86. Franchi F, Ielapi T, Bizzarri M, Seminara P. Embryo extracts opotherapy reduces alpha-fetoprotein levels in hepatocellular carcinoma patients. J Gastroenterol Hepatol 2005;20:1467-8.

87. Livraghi T, Ceriani R, Palmisano A, Pedicini V, Pich MG, Tommasini MA, et al. Complete response in 5 out of 38 patients with advanced hepatocellular carcinoma treated with stem cell differentiation stage factors: Case reports from a single centre. Curr Pharm Biotechnol 2011;12:254-60.

88. Livraghi T, Meloni F, Frosi A, Lazzaroni S, Bizzarri M, Frati L, et al. Treatment with stem cell differentiation stage factors of intermediate-Advanced hepatocellular carcinoma: An open randomized clinical trial. Oncol Res 2005;15:399-408.

89. Cucina A, Biava PM, D'Anselmi F, Coluccia P, Conti F, di Clemente $\mathrm{R}$, et al. Zebrafish embryo proteins induce apoptosis in human colon cancer cells (Caco2). Apoptosis 2006;11:1617-28.

90. Qiao L, Zhao TJ, Wang FZ, Shan CL, Ye LH, Zhang XD. NF-kappaB downregulation may be involved the depression of tumor cell proliferation mediated by human mesenchymal stem cells. Acta Pharmacol Sin 2008;29:333-40.

91. Abdel aziz MT, El Asmar MF, Atta HM, Mahfouz S, Fouad HH, Roshdy NK, et al. Efficacy of mesenchymal stem cells in suppression of hepatocarcinorigenesis in rats: Possible role of Wnt signaling. J Exp Clin Cancer Res 2011;30:49.

92. Abbott DE, Bailey CM, Postovit LM, Seftor EA, Margaryan N, Seftor RE, et al. The epigenetic influence of tumor and embryonic microenvironments: How different are they? Cancer Microenviron 2008;1:13-21.

93. Huang S, Ingber DE. A non-genetic basis for cancer progression and metastasis: Self-organizing attractors in cell regulatory networks. Breast Dis 2007;26:27-54.

94. Bissell MJ, Hall HG, Parry G. How does the extracellular matrix direct gene expression? J Theor Biol 1982;99:31-68.

95. Ramaswamy S, Ross KN, Lander ES, Golub TR. A molecular signature of metastasis in primary solid tumors. Nat Genet 2003;33:49-54.

96. Egeblad M, Werb Z. New functions for the matrix metalloproteinases in cancer progression. Nat Rev Cancer 2002;2:161-74.

97. Benitez A, Yates TJ, Lopez LE, Cerwinka WH, Bakkar A, Lokeshwar VB. Targeting hyaluronidase for cancer therapy: Antitumor activity of sulfated hyaluronic acid in prostate cancer cells. Cancer Res 2011;71:4085-95.

98. Santhanam AN, Baker AR, Hegamyer G, Kirschmann DA, Colburn NH. Pdcd4 repression of lysyl oxidase inhibits hypoxia-induced breast cancer cell invasion. Oncogene 2010;29:3921-32.

99. Zlotogorski A, Dayan A, Dayan D, Chaushu G, Salo T, Vered M. Nutraceuticals as new treatment approaches for oral cancer: II. Green tea extracts and resveratrol. Oral Oncol 2013;49:502-6.

100. Sagar SM, Yance D, Wong RK. Natural health products that inhibit angiogenesis: A potential source for investigational new agents to treat cancer-Part 1. Curr Oncol 2006;13:14-26.

101. Sagar SM, Yance D, Wong RK. Natural health products that inhibit angiogenesis: A potential source for investigational new agents to treat cancer-Part 2. Curr Oncol 2006;13:99-107.
102. Cameron E, Pauling L. Ascorbic acid and the glycosaminoglycans. An orthomolecular approach to cancer and other diseases. Oncology 1973;27:181-92.

103. Cameron E, Pauling L, Leibovitz B. Ascorbic acid and cancer: A review. Cancer Res 1979;39:663-81.

104. Nusgens BV, Humbert P, Rougier A, Colige AC, Haftek M, Lambert CA, et al. Topically applied vitamin $C$ enhances the mRNA level of collagens I and III, their processing enzymes and tissue inhibitor of matrix metalloproteinase 1 in the human dermis. J Invest Dermatol 2001;116:853-9.

105. Block G. Vitamin C and cancer prevention: The epidemiologic evidence. Am J Clin Nutr 1991;53:270S-82.

106. Frei B, Lawson S. Vitamin C and cancer revisited. Proc Natl Acad Sci U S A 2008;105:11037-8.

107. Fritz H, Flower G, Weeks L, Cooley K, Callachan M, McGowan J, et al. Intravenous Vitamin C and cancer: A systematic review. Integr Cancer Ther 2014;13:280-300.

108. Sethi T, Rintoul RC, Moore SM, MacKinnon AC, Salter D, Choo C, et al. Extracellular matrix proteins protect small cell lung cancer cells against apoptosis: A mechanism for small cell lung cancer growth and drug resistance in vivo. Nat Med 1999;5:662-8.

109. Armstrong T, Packham G, Murphy LB, Bateman AC, Conti JA, Fine DR, et al. Type I collagen promotes the malignant phenotype of pancreatic ductal adenocarcinoma. Clin Cancer Res 2004;10:7427-37.

110. Heldin $\mathrm{CH}$, Rubin K, Pietras K, Ostman A. High interstitial fluid pressure-An obstacle in cancer therapy. Nat Rev Cancer 2004;4:806-13.

111. Oldberg A, Kalamajski S, Salnikov AV, Stuhr L, Mörgelin M, Reed RK, et al. Collagen-binding proteoglycan fibromodulin can determine stroma matrix structure and fluid balance in experimental carcinoma. Proc Natl Acad Sci U S A 2007;104:13966-71.

112. Gade TP, Buchanan IM, Motley MW, Mazaheri Y, Spees WM, Koutcher JA. Imaging intratumoral convection: Pressure-dependent enhancement in chemotherapeutic delivery to solid tumors. Clin Cancer Res 2009;15:247-55.

113. Loeffler M, Krüger JA, Niethammer AG, Reisfeld RA. Targeting tumor-associated fibroblasts improves cancer chemotherapy by increasing intratumoral drug uptake. J Clin Invest 2006;116:1955-62.

114. Jain RK. Normalizing tumor vasculature with anti-angiogenic therapy: A new paradigm for combination therapy. Nat Med 2001;7:987-9.

115. Lammerts E, Roswall P, Sundberg C, Gotwals PJ, Koteliansky VE, Reed RK, et al. Interference with TGF-beta1 and -beta3 in tumor stroma lowers tumor interstitial fluid pressure independently of growth in experimental carcinoma. Int J Cancer 2002;102:453-62.

116. Pietras K, Rubin K, Sjöblom T, Buchdunger E, Sjöquist M, Heldin $\mathrm{CH}$, et al. Inhibition of PDGF receptor signaling in tumor stroma enhances antitumor effect of chemotherapy. Cancer Res 2002;62:5476-84.

117. Willett CG, Boucher Y, di Tomaso E, Duda DG, Munn LL, Tong RT, et al. Direct evidence that the VEGF-specific antibody bevacizumab has antivascular effects in human rectal cancer. Nat Med 2004;10:145-7.

118. Egeblad M, Rasch MG, Weaver VM. Dynamic interplay between the collagen scaffold and tumor evolution. Curr Opin Cell Biol 2010;22:697-706.

119. Levental KR, Yu H, Kass L, Lakins JN, Egeblad M, Erler JT, et al. Matrix crosslinking forces tumor progression by enhancing integrin signaling. Cell 2009;139:891-906.

120. Arnold SA, Rivera LB, Miller AF, Carbon JG, Dineen SP, Xie Y, et al. Lack of host SPARC enhances vascular function and tumor spread in an orthotopic murine model of pancreatic carcinoma. Dis Model Mech 2010;3:57-72.

121. Fischbach C, Chen R, Matsumoto T, Schmelzle T, Brugge JS, Polverini PJ, et al. Engineering tumors with 3D scaffolds. Nat Methods 2007;4:855-60. 
122. Mikos AG, Herring SW, Ochareon P, Elisseeff J, Lu HH, Kandel R, et al. Engineering complex tissues. Tissue Eng 2006;12:3307-39.

123. Dvorak HF. Tumors: Wounds that do not heal. Similarities between tumor stroma generation and wound healing. N Engl J Med 1986;315:1650-9.

124. Coussens LM, Werb Z. Inflammation and cancer. Nature 2002;420:860-7.

125. Lam LT, Davis RE, Pierce J, Hepperle M, Xu Y, Hottelet M, et al. Small molecule inhibitors of IkappaB kinase are selectively toxic for subgroups of diffuse large B-cell lymphoma defined by gene expression profiling. Clin Cancer Res 2005;11:28-40.

126. Palladino MA, Bahjat FR, Theodorakis EA, Moldawer LL. Anti-TNF-alpha therapies: The next generation. Nat Rev Drug Discov 2003;2:736-46.

127. Masferrer JL, Leahy KM, Koki AT, Zweifel BS, Settle SL, Woerner BM, et al. Antiangiogenic and antitumor activities of cyclooxygenase-2 inhibitors. Cancer Res 2000;60:1306-11.

128. Harris RE, Beebe-Donk J, Alshafie GA. Reduction in the risk of human breast cancer by selective cyclooxygenase-2 (COX-2) inhibitors. BMC Cancer 2006;6:27.

129. Balkwill F. Cancer and the chemokine network. Nat Rev Cancer 2004;4:540-50.

130. Algra AM, Rothwell PM. Effects of regular aspirin on long-term cancer incidence and metastasis: A systematic comparison of evidence from observational studies versus randomised trials. Lancet Oncol 2012;13:518-27.

131. Thun MJ, Namboodiri MM, Heath CW Jr. Aspirin use and reduced risk of fatal colon cancer 1991;325:1593-6.

132. Reichle A, Vogt T. Systems biology: A therapeutic target for tumor therapy. Cancer Microenviron 2008;1:159-70.

133. Roche-Nagle G, Connolly EM, Eng M, Bouchier-Hayes DJ, Harmey JH. Antimetastatic activity of a cyclooxygenase-2 inhibitor. Br J Cancer 2004;91:359-65.

134. Hafner C, Reichle A, Vogt T. New indications for established drugs: Combined tumor-stroma-targeted cancer therapy with PPARgamma agonists, COX-2 inhibitors, mTOR antagonists and metronomic chemotherapy. Curr Cancer Drug Targets 2005;5:393-419.

135. TroskoJE. Gapjunction intercellular communication as a 'Biological Rosetta Stone' in understanding, in a systems manner, stem cell behavior, mechanisms of epigenetic toxicology, chemoprevention and chemotherapy. J Membr Biol 2007;218:93-100.

136. Decker EA. Phenolics: Prooxidants or antioxidants? Nutr Rev 1997;55:396-8.

137. Babich H, Schuck AG, Weisburg JH, Zuckerbraun HL. Research strategies in the study of the pro-oxidant nature of polyphenol nutraceuticals. J Toxicol 2011;2011:467305.

138. Osseni RA, Rat P, Bogdan A, Warnet JM, Touitou Y. Evidence of prooxidant and antioxidant action of melatonin on human liver cell line HepG2. Life Sci 2000;68:387-99.

139. Dinicola S, Cucina A, Antonacci D, Bizzarri M. Anticancer effects of grape seed extract on human cancers: A review. J Carcinog Mutagen 2014;S8:60-70.

140. Bizzarri M, Proietti S, Cucina A, Reiter RJ. Molecular mechanisms of the pro-apoptotic actions of melatonin in cancer: A review. Expert Opin Ther Targets 2013;17:1483-96.

141. Altucci L, Gronemeyer H. The promise of retinoids to fight against cancer. Nat Rev Cancer 2001;1:181-93.

142. Stern R. Hyaluronan metabolism: A major paradox in cancer biology. Pathol Biol (Paris) 2005;53:372-82.

143. Payne SL, Hendrix MJ, Kirschmann DA. Paradoxical roles for lysyl oxidases in cancer - A prospect. J Cell Biochem 2007;101:1338-54.

144. Halliwell B. Vitamin C: Antioxidant or pro-oxidant in vivo? Free Radic Res 1996;25:439-54.

145. Chen Q, Espey MG, Krishna MC, Mitchell JB, Corpe CP, Buettner GR, et al. Pharmacologic ascorbic acid concentrations selectively kill cancer cells: Action as a pro-drug to deliver hydrogen peroxide to tissues. Proc Natl Acad Sci U S A 2005;102:13604-9.

146. Moses HL, Yang EY, Pietenpol JA. TGF-beta stimulation and inhibition of cell proliferation: New mechanistic insights. Cell 1990;63:245-7.

147. Tian M, Schiemann WP. The TGF-beta paradox in human cancer: An update. Future Oncol 2009;5:259-71.

148. Bierie B, Moses HL. Tumour microenvironment: TGFbeta: The molecular Jekyll and Hyde of cancer. Nat Rev Cancer 2006;6:506-20.

149. Grinnell F, Ho CH. Transforming growth factor beta stimulates fibroblast-collagen matrix contraction by different mechanisms in mechanically loaded and unloaded matrices. Exp Cell Res 2002;273:248-55.

150. Albini A, Sporn MB. The tumour microenvironment as a target for chemoprevention. Nat Rev Cancer 2007;7:139-47.

151. Joyce JA. Therapeutic targeting of the tumor microenvironment. Cancer Cell 2005;7:513-20.

152. Bissell MJ, Radisky D. Putting tumours in context. Nat Rev Cancer 2001;1:46-54.

153. Blansfield JA, Caragacianu D, Alexander HR $3^{\text {rd }}$, Tangrea MA, Morita SY, Lorang D, et al. Combining agents that target the tumor microenvironment improves the efficacy of anticancer therapy. Clin Cancer Res 2008;14:270-80.

How to cite this article: ???

Source of Support: Nil, Conflict of Interest: None declared. 